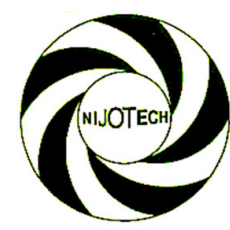

Nigerian Journal of Technology (NIJOTECH)

Vol. 35, No. 1, January 2016, pp. 122 - 128

Copyright@ Faculty of Engineering, University of Nigeria, Nsukka,

Print ISSN: 0331-8443, Electronic ISSN: 2467-8821

www.nijotech.com

http://dx.doi.org/10.4314/njt.v35i1.19

\title{
INFLUENCE OF IRON CONTENT AND PLASTIC DEFORMATION ON THE MECHANICAL PROPERTIES OF 8011-TYPE Al-Fe-Si ALLOY
}

\author{
0. H. Yakubu1, I. Usman ${ }^{2}$, A. Aliyu ${ }^{3}$ and O. O. Emmanuel ${ }^{4}$ \\ 1,2,3,4 Dept of Metallurgical and Materials EnGR., Ahmadu Bello University, Zaria, Kaduna State NigERIA. \\ Email-addresses:11 yhassan27@yahoo.com, 2 mannusman@yahoo.com, 3 ayubaihima@yahoo.com, \\ 4 ojimatrix1@yahoo.com
}

\begin{abstract}
This paper examines the effect of iron content and plastic deformation on the mechanical properties of wrought AlFe-Si alloy. Seven samples each of dimension $240 \mathrm{~mm} \times 140 \mathrm{~mm} \times 7 \mathrm{~mm}$ were cast for each aluminium alloy plate containing iron content of $0.708 \%, 0.909 \%$ and $0.931 \%$ by chill casting method. As-received commercial aluminium alloy 8011 has an iron content of $0.857 \%$ and it was cut into seven samples of the same geometry. Cold rolling experiment was carried out from $30 \%$ to $80 \%$ reduction in thickness. The mechanical properties of the alloys were investigated. The results showed that the maximum ultimate tensile strength obtained for alloys $0.708 \% \mathrm{Fe}$ and $0.857 \%$ Fe were $171.45 \mathrm{MPa}$ and176.45MPa respectively both occurred at $60 \%$ reduction in thickness while alloys $0.909 \% \mathrm{Fe}$ and $0.931 \% \mathrm{Fe}$ respectively have $163.16 \mathrm{MPa}$ and $170.00 \mathrm{MPa}$ at $80 \%$ reduction in thickness. An increase in iron content led to corresponding decrease in tensile strength but at $80 \%$ reduction in thickness, the strength increase with iron content for alloys of $0.9 \% \mathrm{Fe}$ and above. The micro-vicker hardness values increases, reaching the peak and then decreases with increasing percentage deformation.
\end{abstract}

Keywords. aluminium, iron, Mechanical properties, UTS, percentage deformation.

\section{INTRODUCTION}

Aluminium alloy 8xxx series have found wider application in construction industries and automobile as a result of their good physical and chemical properties such as formability, corrosion, light weight and also because it is possible to control the micro structural composition of the alloy by means of specific thermal and mechanical treatments [1].

The iron composition of 8011 aluminium alloy ranges from $0.6-1 \%$ has greatly influenced the mechanical properties of the alloy. During metalworking, the optimum level of the iron that will not impact any negative effect to the ductility of the alloy is highly required in order to avoid some defects such as cracking due to the low level of material ductility. The processing capabilities of the aluminium alloy and/or the strength of the final wrought product are greatly influenced by the level of iron content [2].

In aluminium alloy, a large number of iron-containing intermetallic phases have been identified in the microstructures, depending on the solidification conditions and alloy composition. Although iron is highly soluble in liquid aluminium and its alloys, it has very little solubility in the $\alpha$-Al solid $(0.05 \mathrm{wt} \%)$, and so it tends to combine with other elements to form intermetallic phase particles of various types [2]. In the absence of silicon, the dominant phases that form are $\mathrm{Al}_{3} \mathrm{Fe}$ and $\mathrm{Al}_{6} \mathrm{Fe}$, but when $\mathrm{Si}$ is present, the dominant phases are $\mathrm{Al}_{8} \mathrm{Fe}_{2} \mathrm{Si}$ (known as alpha- or $\alpha$-phase) and $\mathrm{Al}_{5} \mathrm{FeSi}$ (known as beta- or $\beta$-phase). If $\mathrm{Mg}$ is also present with $\mathrm{Si}$ alternative phase called pi- or $\pi$-phase can form $\mathrm{Al}_{8} \mathrm{FeMg}_{3} \mathrm{Si}_{6}$ [2]. Another common phase that forms when $\mathrm{Mn}$ is present with $\mathrm{Si}$ is $\mathrm{Al}_{15}(\mathrm{Fe}, \mathrm{Mn})_{3} \mathrm{Si}_{2}$, also confusingly known as $\alpha$-phase [2]. This phase tends to form in preference to other $\alpha$-phases whenever $\mathrm{Mn}$ is present. There are also other rarer phases which form when other elements are present, e.g. $\mathrm{Ni}, \mathrm{Co}, \mathrm{Cr}, \mathrm{Be}$. When these low symmetry compounds crystallize, they are prone to grow into long needles/plates that are extremely detrimental to both strength and ductility [3].

The effect of iron on the mechanical properties of Alalloys has been extensively investigated [4] and they consistently reported that as iron level increases, the 
ductility of Al-Si based alloys decreases. This is usually accompanied by an increase in tensile strength, however, the yield stress become unaffected by iron, unless the ductility is affected so much that the alloy cannot even reach yield before brittle fracture occurs. Investigation on the effect of intensive forced melt convection on mechanical properties of Fe-containing Al-Si based alloys have been carried out [5]. They observed that as the the equilibrium solid solubility of Fe in the $\mathrm{Al}$ solid solution $(\alpha-\mathrm{Al})$ is low, Fe exists in $\mathrm{Al}-$ alloys in the form of Fe-bearing intermetallic compounds. In commercial Al-Si based cast alloys, these compounds are often of the morphologies, either as long needles or large plates, which drastically reduce the ductility of the alloys.

Chemically, this detrimental effect of iron in aluminium alloys can be minimized by limiting the maximum content of the Fe impurity, or by alloying with other element such as manganese [6]. Alloying with $0.9 \% \mathrm{Mn}$ resulted in apparent fragmentation of the $\beta$ - $\mathrm{Al}_{5} \mathrm{FeSi}$-needles [7].

The work carried out on the effect of iron in Al-Si casting alloys [2] concluded that wherever possible, iron level in Al-Si alloys should be kept at the bearable minimum level in order to avoid the detrimental effect on mechanical properties, particularly ductility and fracture toughness.

Investigation on the effect of cold rolling on bending and tensile behaviour of 7075 aluminium alloy [8] observed that after $58 \%$ cold working, there was a rapid increase in yield strength of $119.25 \%$ due to high density of dislocations. In addition, increases in the tensile strength and hardness value with decrease in percentage elongation of the rolled material were observed. The effect of hot cumulative roll bonding process on the mechanical properties of AA 5058 [9] revealed that the strength of the sheet increased considerably by the first two ARB cycles which is attributed to work hardening caused by an increase in dislocation density and sub-grains.

The aim of this present study is to investigate the influence of iron content and plastic deformation on the mechanical property of the AA 8011 in order to ascertain the optimum iron level that will give the best mechanical property of the rolled products.

\section{EXPERIMENTAL PROCEDURE}

Seven aluminium alloy plates each of dimension $240 \mathrm{~mm} \times 140 \mathrm{~mm} \times 7 \mathrm{~mm}$ were cast for each aluminium alloy of varying iron contents $0.708 \% \mathrm{Fe}$, $0.909 \% \mathrm{Fe}$ and $0.931 \% \mathrm{Fe}$ labelled as $\mathrm{A}, \mathrm{B}$ and $\mathrm{C}$ respectively by melting appropriate quantities of aluminium wires with other alloying elements appropriately added. The melt was heated to a temperature of $720^{\circ} \mathrm{C}$ and then brought from the furnace before magnesium was added and stirred vigorously. The molten alloy was cast into metallic moulds and after cooling, the bolts used to tight the moulds were unscrewed to removed the samples. The as-received commercial aluminium alloy 8011 of $0.857 \% \mathrm{Fe}$ was cut into seven pieces of the same dimension as previously highlighted. This alloy was labelled as alloy AR. The chemical compositions of the alloys are shown in Table 1.

The rolling operation was carried out using four-high commercial rolling mill. A total of 24 samples were annealed at $450^{\circ} \mathrm{C}$ for one hour. Each plate was fed directly between the work rolls, which imposed no forward or back tension loads on the plate. The alloys were cold-rolled from $7 \mathrm{~mm}-1.4 \mathrm{~mm}$ i.e. $30 \%-80 \%$ reductions in thickness.

Tensile strength measurement was conducted on a Hounsfield Tensometer Machine. The tensile test samples with gauge dimension $100 \mathrm{~mm} \times 40 \mathrm{~mm} \times$ $10 \mathrm{~mm}$ were machined from the as-cast and as-received samples.

The impact test was done on Charpy Impact Testing Machine of capacity 25J. A V-notch was machined into a $10 \mathrm{~mm}$ wide and $100 \mathrm{~mm}$ long test specimen and the depth of the notch is $4 \mathrm{~mm}$.

The hardness of the samples was carried out with Micro-vicker Hardness Tester of capacity 5kgf using a load of $0.3 \mathrm{kgf}$ to indent the samples for about 15 seconds.

Table 1: Chemical compositions of as-cast and as-received aluminium alloys 8011

\begin{tabular}{ccccccccccc}
\hline Alloy & $\mathrm{Al}$ & $\mathrm{Fe}$ & $\mathrm{Si}$ & $\mathrm{Mn}$ & $\mathrm{Cu}$ & $\mathrm{Mg}$ & $\mathrm{Ti}$ & $\mathrm{Zn}$ & $\mathrm{Pb}$ & $\mathrm{Cr}$ \\
\hline $\mathrm{A}$ & Balance & 0.708 & 0.551 & 0.117 & 0.072 & 0.020 & 0.015 & 0.120 & 0.015 & 0.050 \\
$\mathrm{AR}$ & Balance & 0.857 & 0.551 & 0.117 & 0.072 & 0.020 & 0.015 & 0.120 & 0.015 & 0.050 \\
$\mathrm{~B}$ & Balance & 0.909 & 0.551 & 0.117 & 0.072 & 0.020 & 0.015 & 0.120 & 0.015 & 0.050 \\
$\mathrm{C}$ & Balance & 0.931 & 0.551 & 0.117 & 0.072 & 0.020 & 0.015 & 0.120 & 0.015 & 0.050 \\
\hline
\end{tabular}




\section{RESULTS AND DISCUSSION}

\subsection{Aluminium Alloy Sample with $0.708 \% \mathrm{Fe}$}

The stress-strain curves shown in Figure 1 revealed that the ultimate tensile strength(UTS) of the samples deformed from $40 \%-70 \%$ are in the ranges of 161 MPa-171.45MPa while the samples deformed at $30 \%$ and $80 \%$ have the values of $130.31 \mathrm{MPa}$ and $115 \mathrm{MPa}$ respectively.

The variation of ductility with percentage deformation (Figure 2) showed that ductility of the samples increased from $30 \%$ to $40 \%$ and then decreased with increase in percentage deformation.

The impact strength decreases progressively with increase in percentage deformation (Figure 3)

The graph showed increase in hardness values with increase in percentage deformation up to $70 \%$ and then decreased (Figure 4).

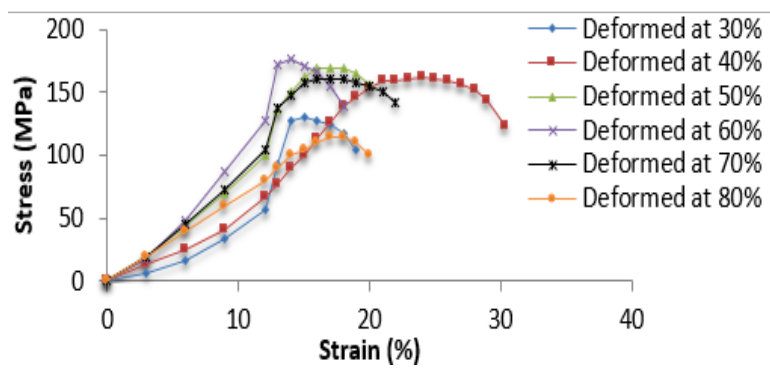

Figure 1: Stress-Strain Curves of Samples with $0.708 \% \mathrm{Fe}$

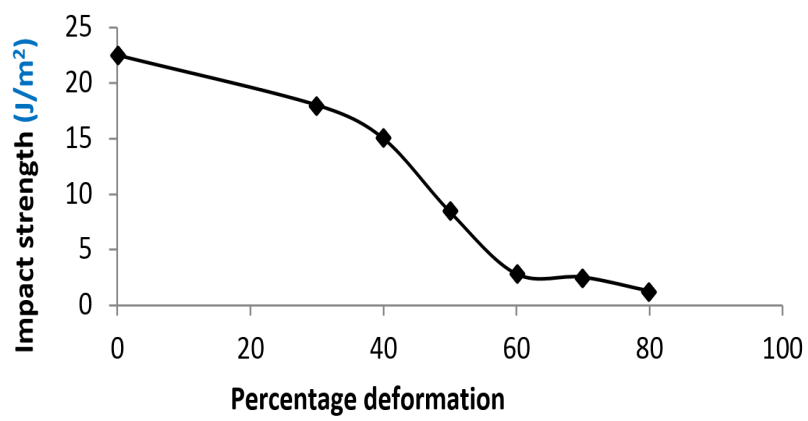

Figure 3: Variation of Impact Strength with \% Deformation of Samples with $0.708 \% \mathrm{Fe}$

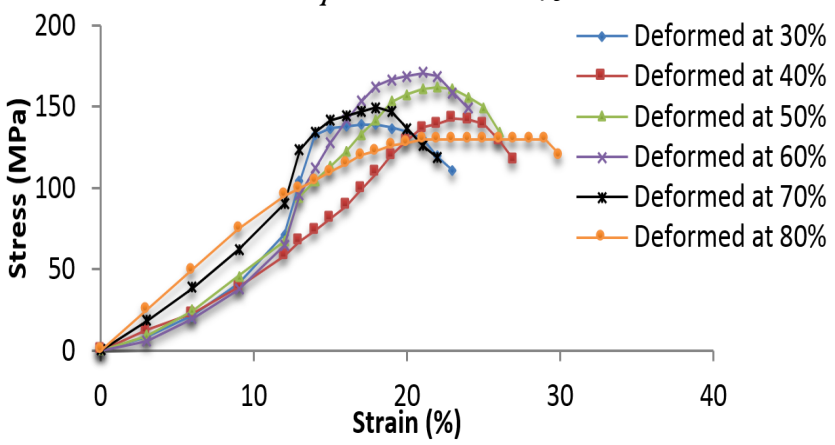

Figure 5: Stress-strain curves of samples with $0.857 \% \mathrm{Fe}$

\subsection{Aluminium Alloy Sample with $0.857 \% \mathrm{Fe}$}

Figure 5 showed that the samples deformed at $50 \%$ and $60 \%$ revealed the UTS of $162.26 \mathrm{MPa}$ and 176.45MPa respectively while the UTS in the ranges of $130 \mathrm{MPa}-149.48 \mathrm{MPa}$ were displayed for the other samples.

The graph displayed an increase in ductility from $30 \%$ to $40 \%$ and further decreased with increase in percentage deformation (Figure 6). Figure 7 revealed decrease in impact strength with increased percentage deformation.

The hardness values of the samples increase with increase percentage deformation up to $60 \%$ and then decrease (Figure 8).

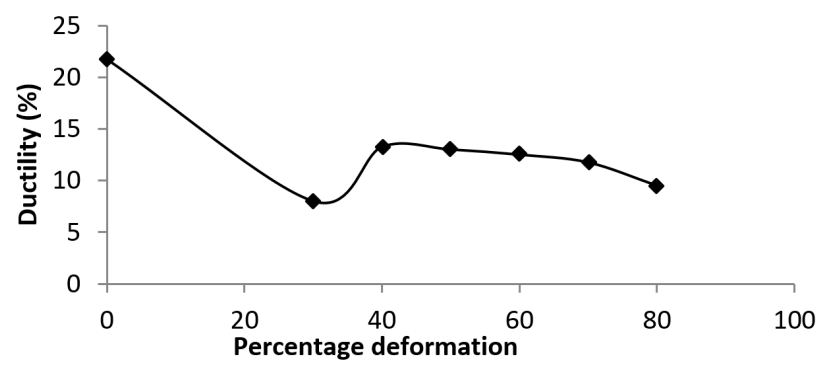

Figure 2: Variation of Ductility with \% Deformation of Samples with $0.708 \% \mathrm{Fe}$

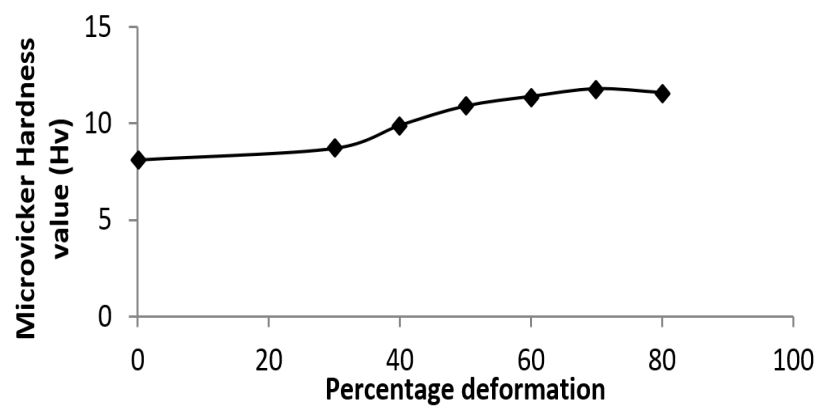

Figure 4: Variation of Hardness with \% Deformation of Samples with $0.708 \% \mathrm{Fe}$

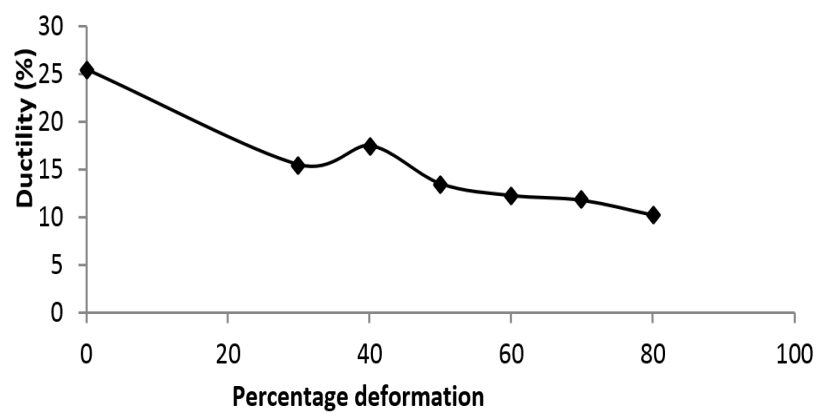

Figure 6: Variation of Ductility with \% Deformation of Samples with $0.857 \% \mathrm{Fe}$ 


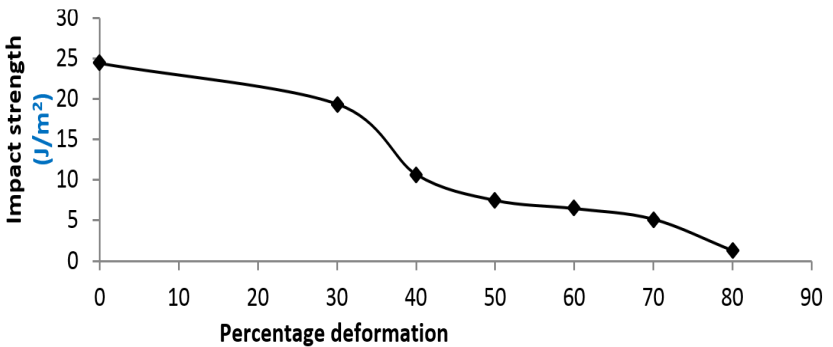

Figure 7: Variation of Impact Strength with \%

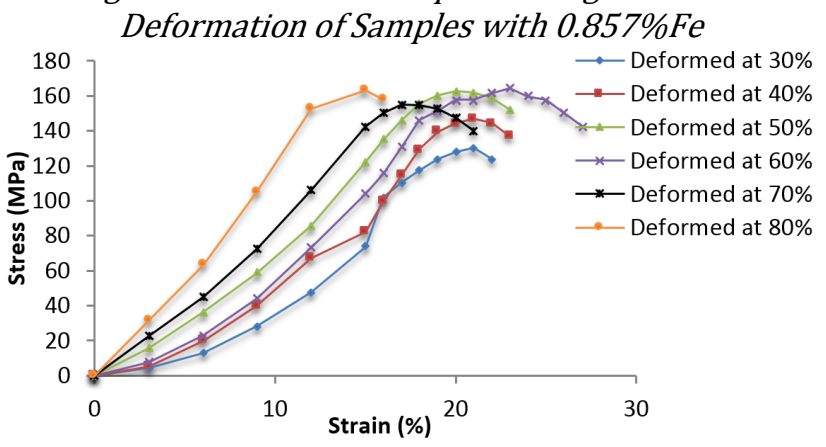

Figure 9: Stress-strain curves of samples with $0.909 \% \mathrm{Fe}$

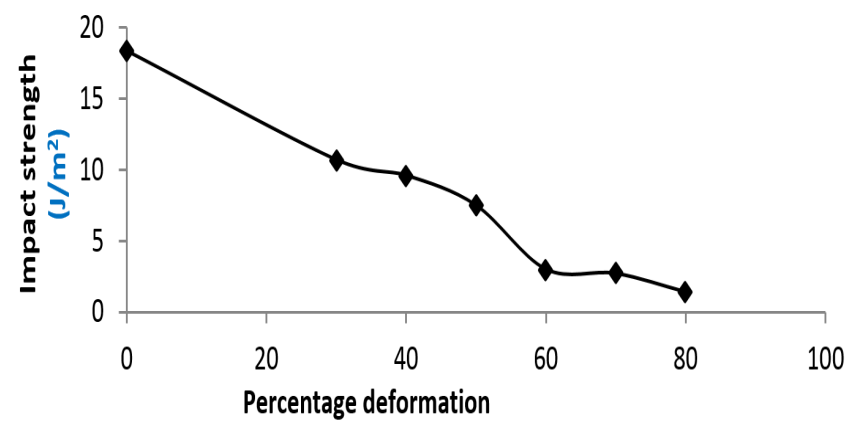

Figure 11: Variation of Impact Strength with \% Deformation of Samples with $0.909 \% \mathrm{Fe}$

\subsection{Aluminium Alloy Sample with $0.909 \% \mathrm{Fe}$}

The samples deformed at $50 \%-80 \%$ showed values of UTS of $155 \mathrm{MPa}-163.16 \mathrm{MPa}$ while the samples deformed at $30 \%$ and $40 \%$ revealed the values of $130.21 \mathrm{MPa}$ and $146.84 \mathrm{MPa}$ respectively (Figure 9). The graph displayed an increase in ductility from $30 \%$ to $40 \%$ and then showed decrease in ductility with increased percentage deformation (Figure 10).

The impact strength of the samples decreased with increase in percentage deformation (Figure 11). The graph showed increase in hardness values up to $50 \%$ and then decreases (Figure 12).

\subsection{Aluminium Alloy Sample with 0.931\%Fe}

The values of UTS of 135.31MPa and 132.64MPa were displayed by samples deformed at $30 \%$ and $70 \%$ respectively while the other samples are in the ranges of $156.35 \mathrm{MPa}-170 \mathrm{MPa}$ (Figure 13). The ductility increased from $30 \%$ to $40 \%$ followed by decrease in ductility which later showed an increment at $80 \%$

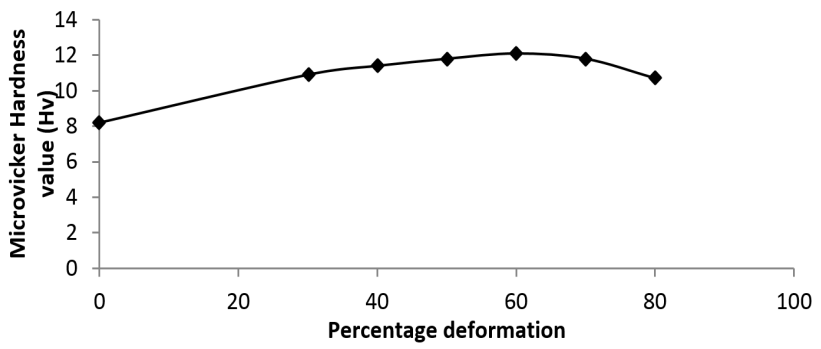

Figure 8: Variation of Hardness with \% Deformation of

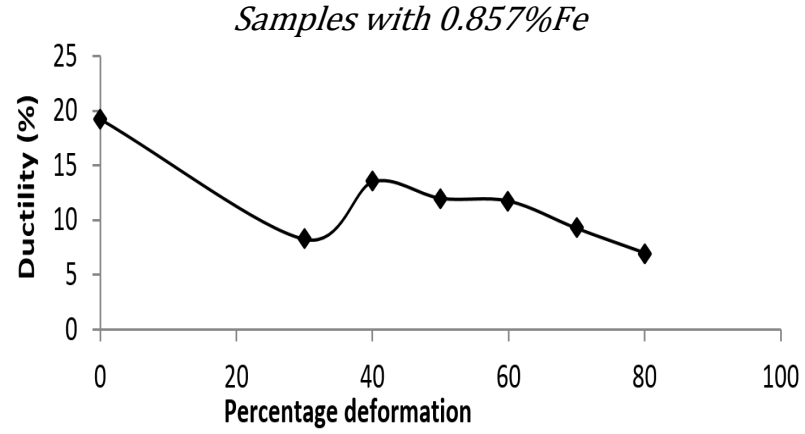

Figure 10: Variation of Ductility with \% Deformation of Samples with $0.909 \% \mathrm{Fe}$

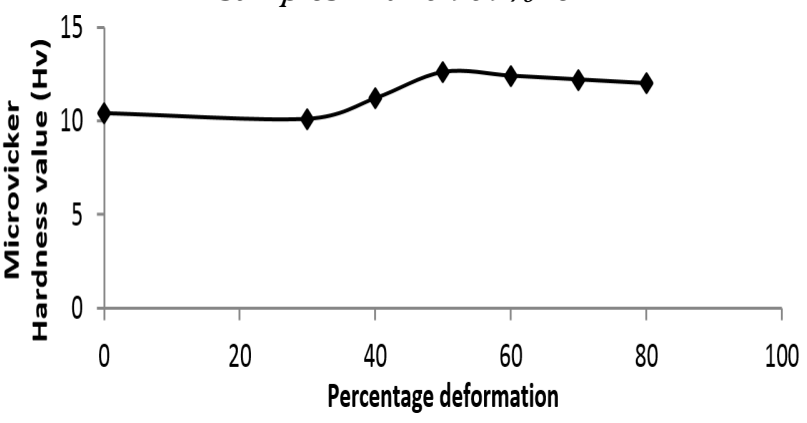

Figure 12: Variation of Hardness with \% Deformation of Samples with $0.909 \% \mathrm{Fe}$

(Figure 14). Increase in impact strength with decreasing percentage deformation was observed (Figure 15). The hardness values increased up to $40 \%$ and then decreased with increasing percentage deformation (Figure 16).

\subsection{Effect of Iron Content and Plastic Deformation on Ultimate Tensile Strength of Cold-rolled AA8011}

The effect of alloying elements contributes greatly to the mechanical properties of the metal. When the iron content increase from $0.708 \%$ to $0.857 \%$, there was progressive increases in UTS from $171.45 \mathrm{MPa}$ to $176.45 \mathrm{MPa}$ respectively and both occurred at $60 \%$ percentage deformation (Figures 1 and 5). The increased in strength as iron content increase is due to interaction of dislocations and precipitate particles. 


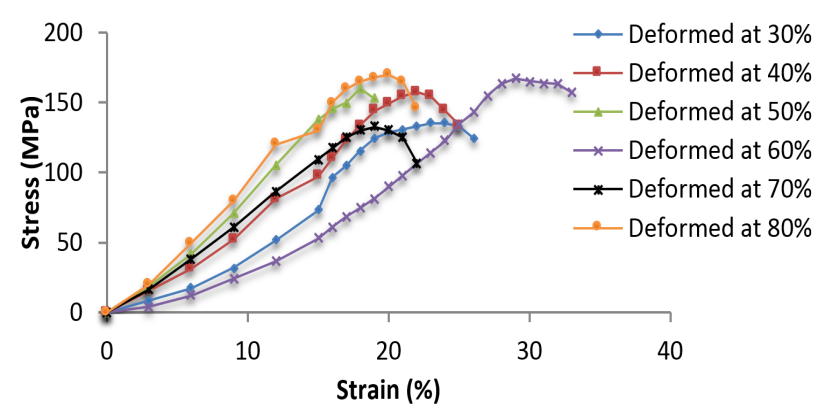

Figure 13: Stress-Strain Curves of samples with $0.931 \% \mathrm{Fe}$

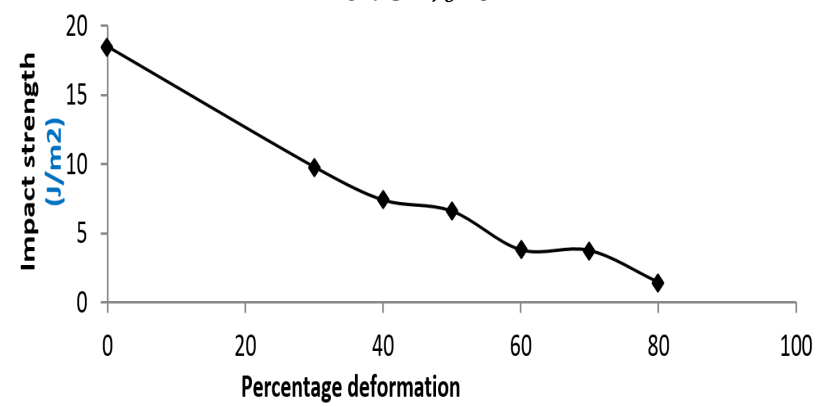

Figure 15: Variation of Impact Strength with \% Deformation of Samples with $0.931 \% \mathrm{Fe}$

The intermetallic particles in precipitation hardening hinder the motion of dislocations there by leading to strength increment. Further increase in iron content up to $0.908 \%$ and $0.931 \%$ resulted in deterioration of tensile property although UTS of $163.16 \mathrm{MPa}$ and $170 \mathrm{MPa}$ respectively later resurfaced at $80 \%$ deformation (Figures 13 and 14).

The rapid increased of the values of the UTS of the samples cold-rolled up to $60 \%$ could be attributed to the complicated array of defects such as high density of dislocations produced in the alloys during deformation.

The deterioration in tensile strength as iron content increases might be due to release of stress carried by the second phase particles. When crack occurs in these particles, it affects the overall load bearing capacity of the alloys and hence, it limits its work hardening bebaviour since the flow stress increase in the matrix leads to a higher level of load transfer to the second phase intermetallic particles as have been previously reported [10]. The reason for further increment in tensile strength at $80 \%$ deformation for samples with iron contents of $0.908 \%$ and $0.931 \%$ could be attributed to high level of grains boundaries in the microstructure as a result of large quantity of intermetallic particles which fragmented into fine grains by plastic deformation.

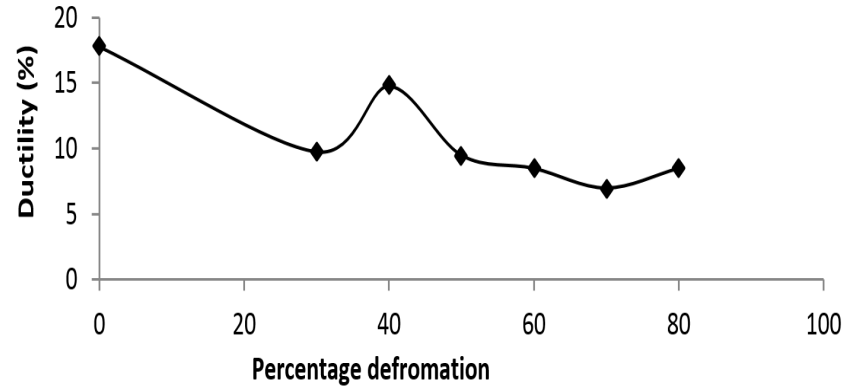

Figure 14: Variation of ductility with \% deformation of samples with $0.931 \% \mathrm{Fe}$

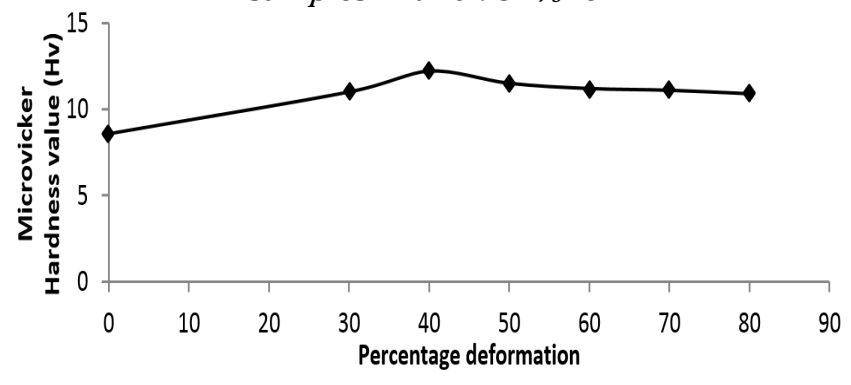

Figure 16: Variation of hardness with \% deformation of samples $0.931 \% \mathrm{Fe}$

\subsection{Effect of Iron Content and Plastic Deformation on Ductility of Cold-rolled AA8011}

The variation of ductility with \% deformation generally showed increases in ductility from $30 \%$ to $40 \%$ irrespective of iron content (Figures 2, 6, 10 and 14). The simultaneous increase in ductility of the alloys from $30 \%$ to $40 \%$ could be attributed to the microstructural changes occurring during deformation process.

Investigation on the mechanical properties of an alloy after equal channel angular extrusion [11] reported that the grains with high grain boundaries impeded the motion of dislocations and hence improved the strength of the materials and at the same time, the fine grains formed during deformation might facilitate an increase in grain boundary sliding and hence grain rotation which could improve ductility. The increased in ductility from $30 \%$ to $40 \%$ deformations therefore should have been linked to grain boundaries sliding as observed in the previous research work [11].

Beyond $40 \%$ reduction in thickness, the alloys displayed decrease in ductility with increasing percentage deformation and this might be due to dislocations generation which interacted and impeded each other and hindering their motion, thereby decreasing the ductility of the alloys. 


\subsection{Effect of Iron Content and Plastic Deformation on Impact Strength of Cold-rolled AA8011}

The impact strength of the samples decreased progressively with increase in percentage deformation and iron content (Figures 3, 7, 11 and 15). This is attributed to dislocation generation and interaction. During cold rolling of the alloys, dislocation density increases as the degree of deformation increases; the fragmentation of interdendritic particles also occur. Due to the interaction of dislocations with each other and with impurities, there is increase in work hardening rate, resulting in an increase in both the strength and hardness values but loss in ductility and this may seriously reduces the toughness property of the alloys. The decrease in toughness with increased iron content could be due to high concentration of iron-rich intermetallic phase particles, suggesting a higher potential for fracture by the mechanism of coalescence when subjected to impact load and this is in agreement with the previous work [8].

\subsection{Effect of Iron Content and Plastic Deformation on Hardness of Cold-rolled AA8011}

The micro-vicker hardness values of the investigated alloy samples with iron content $0.708 \%, 0.857 \%$, $0.909 \%$ and $0.931 \%$ increases progressively and reached peak levels at $70 \%, 60 \%, 50 \%$ and $40 \%$ deformations respectively (Figures 4, 8, 12, 16). After the attainment of these peak levels of hardness property, all samples displayed decrease in hardness with increasing percentage deformation.

The general increase in hardness values could be attributed to strain hardening tendency of the alloy samples under investigation caused by cold rolling operation whereas the decrease in hardness after large deformation is as a result of decrease in dislocation density in the interior of subgrains. This observation is in agreement with previous work [12] who reported that dislocation density in the interiors of the grain decrease with increase in strain leading to a situation in most interiors of the grains to become eventually free of dislocation after a large deformation resulting to a reduced hardness value.

\subsection{Effect of Iron Content and Plastic Deformation on Microstructure of Cold-rolled AA8011}

The micrographs of as-cast and as-received samples shown in Plate 1 revealed that the aluminium matrix contained volume fractions of intermetallic phases predominately $\mathrm{FeAl}_{3}$ and AlFeSi crystals. These crystals are finely dispersed within the matrix phase. The crystals become larger in size and form interdendritic network as iron content in the alloy increases. The grains of as-received alloy cast by twinroll casting method are finer than the as-cast alloys cast by chill casting method because of the segregation of alloying elements at approximately the centre of the strip thickness due to the shearing action of the rolls on the formed dendrites.
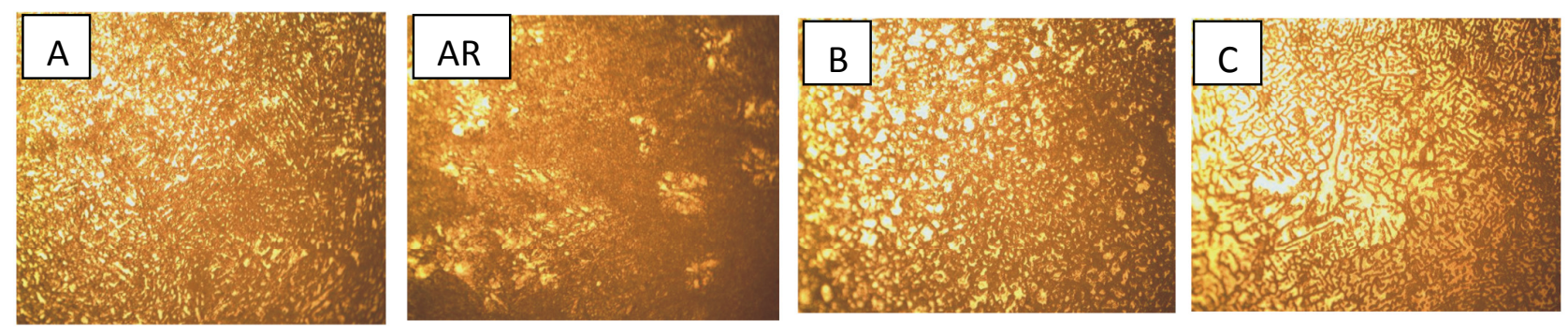

Plate 1: Optical micrographs of as-received and as-cast samples of AA 8011 of various levels of iron content; white spots are interdendritic of intermetallic particles distributed in aluminium matrix (yellow back-ground). X100
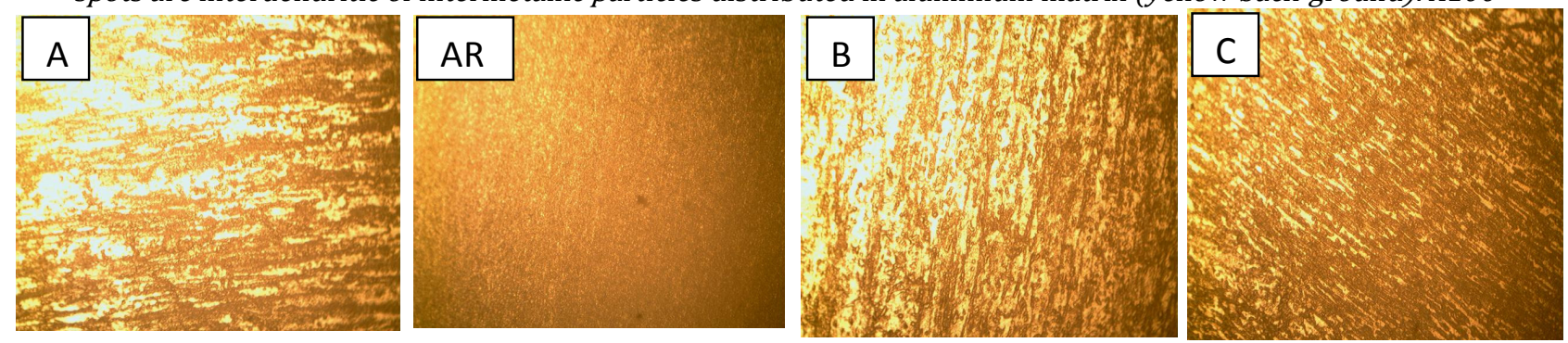

Plate 2: Optical micrographs of samples cold-rolled to 80\%; white spots are fragmentation of interdendritic particles elongated along rolling direction in aluminium matrix (yellow back-ground). X100 
With an increased in percentage deformation up to $80 \%$ (Plate 2), the fragmented grains become finer being elongated in the rolling direction and this justify good mechanical properties obtained in the alloys at higher deformation. The redistribution of impurities that occurred during the rolling process resulted in segregation reduction observed in the cold-rolled samples.

\section{CONCLUSIONS}

Based on the research finding, the following conclusions were drawn

i. The maximum UTS obtained for alloys $0.708 \% \mathrm{Fe}$ and $0.857 \% \mathrm{Fe}$ were $171.45 \mathrm{MPa}$ and $176.45 \mathrm{MPa}$ respectively both occurred at $60 \%$ deformation while alloys $0.909 \% \mathrm{Fe}$ and $0.931 \% \mathrm{Fe}$ respectively have $163.16 \%$ and $170.00 \mathrm{MPa}$ at $80 \%$ deformation.

ii. At higher percentage deformation of $80 \%$, samples of AA 8011 containing more than $0.9 \% \mathrm{Fe}$ revealed higher tensile strength.

iii. The hardness value increase as percentage deformation increased and after reaching the peak hardness values, all samples displayed decrease in hardness with increasing percentage deformation indicating that AA 8011 exhibit softening characteristics.

v. The alloys also possess excellent ductility as a results of its soften characteristics.

\section{ACKNOWLEDGMENTS}

The present study was technically supervised by Professor A. K. Oyinlola of Ahmadu Bello University, Zaria Nigeria. The selfless services are gratefully appreciated by the authors.

\section{REFERENCES}

1. Xing Z. P., Kang S. B. and Kim H. W.: "Softening Behavior of 8011 Alloy Produced by Accumulative Roll Bonding Process", Scripta Material 45, 2001,pp 597-604.

2. John A. T.: "The Effect of Iron in Al-Si Casting Alloy", Cooperative Research Centre for Cast Metals
Manufacturing (CAST), the University of Queensland, Brisbane, Australia, 2009,pp 1-10.

3. Zhang H.: "Effect of Iron on the Microstructure and Mechanical Properties of Al-Si Alloys", the Minerals, Metals and Materials Society, Shanghai, China, 2007,pp 775-780.

4. Mbuya T. O., Odera B. O. and Nganga S. P.: "Influence of Iron on Castability and Properties of Aluminium Silicon Alloys", International Journal of Cast Metals Research, 16(5), 2003, pp 45-465.

5. Fang X., Shao G., Liu Y. Q. and Fan Z.: "Effects of Intensive Forced Melt Convection on the Mechanical Properties of Fe-containing Al-Si based Alloys" ,Brunel Centre for Advanced Solidification Technology (BCAST), Brunel University, Uxbridge, Middlesex, UB8 3PH, UK, 2011,pp 1-11.

6. Lu L. and Dahel A. K.: "Iron-rich Intermetallic Phases and their Role in Casting Defect Formation in Hypoeutectic Al-Si Alloys", Metallurgical and Materials Transactions, 36A, 2005, pp 819-835.

7. Shabestari S. G., Mohammed M., Emamy M. and Campbell J.: "Effect of Mn and Sr on Intermetallics in Fe-rich Eutectic Al-Si Alloys", International Journal of cast Metal Research, 15(1), 2002,pp 17-24.

8. Tajally M., Huda Z. and Masjuki H. H.: "Effect of cold rolling on bending and tensile behaviour of 7075 aluminum alloy", Journal of Applied Sciences, 9, (2009), pp 3888-3893.

9. Hassan S. and Ebrahim P.: "Effect of hot cumulative roll bonding on the mechanical properties of AA 5058", Open Journal of Metal, 1, 2011, pp 12 - 15.

10. Salem S.: "The influence of Iron on the Microstructure and Mechanical Properties of Cast Al-Si Alloys", Unpublished Ph.D Thesis, Jonkoping University, The School of Engineering Component Technology, Sweden, 2007.

11. Akshay G. P. and Ibrahim M.: "Mechanical Properties of Zn-9\%Al-3\%Cu Alloy after Equal Channel Angular Extrusion", Proceedings of the XIth International Congress and Exposition, Society for Experimental Mechanics Inc. Orlando, Florida USA, 2008, pp 1-7.

12. Chang J. Y. and Shan A.: "Microstructure and Mechanical Properties of AlMgSiAlloys after Equal Channel Angular Pressing at Room Temperature", Materials Science and Engineering Journal, A327, 2003, pp165-170. 